[2] Jordan S, Distler JHW, Maurer B, Huscher D, Laar JM Van, Allanore Y, et al. Effects and safety of rituximab in systemic sclerosiss: an analysis from the European Scleroderma Trial and Research (EUSTAR) group. 2014;1-

Acknowledgement: Work done in "CBmed" was funded by the Austrian Federal Government within the COMET K1 Centre Program, Land Steiermark and Land Wien.

Disclosure of Interests: Barbara Dreo: None declared, Barbara Prietl: None declared, Selina Kofler: None declared, Harald Sourij: None declared, Angelika Lackner: None declared, Florentine Fürst-Moazedi: None declared, Monica D'Orazio: None declared, Martin Stradner Speakers bureau: Novartis, Roche, Lilly, BMS,Pfizer, Shire, Winfried Graninger: None declared, Hans-Peter Brezinsek: None declared

DOI: 10.1136/annrheumdis-2019-eular.8047

\section{SAT0273 PREDICTIVE VALUE OF THE REVISED EUROPEAN SCLERODERMA TRIALS AND RESEARCH GROUP ACTIVITY INDEX (EUSTAR-AI)}

Serena Fasano ${ }^{1}$, Veronica Giacco ${ }^{1}$, Antonella Riccardi ${ }^{1}$, Valentina Messiniti ${ }^{1}$, Alessandra Vacca ${ }^{2}$, Oliver Distler ${ }^{3}$, Otylia Kowalka Bielecka ${ }^{4}$, Yannick Allanore ${ }^{5}$, Gabriele Valentini ${ }^{1}$, European Scleroderma Trials and Research group (EUSTAR) co-authors. 'University of Campania "Luigi Vanvitelli", Rheumatology, Naples, Italy ${ }^{2}$ University Hospital of Cagliari, Rheumatology, Cagliari, Italy, ${ }^{3}$ University Hospital Zurich, Rheumatology, Zurich, Switzerland; ${ }^{4}$ Medical University of Bialystok, Rheumatology and Internal Medicine, Bialystok, Poland; ${ }^{5}$ Cochin Hospital, Paris Descartes University, Rheumatology, Paris, France

Background: Disease activity as measured by the European Scleroderma Study Group Activity Index (EScSG-AI) (1) has been recently found to predict the development of damage over time in an early systemic sclerosis (SSc) cohort (2). The European Scleroderma Trials and Research Group Task Force for the Development of Revised Activity Criteria for SSc recently succeeded in identifying a preliminarily revised activity index (EUSTAR-AI) that had a greater construct validity than the EScSG-AI i.e. performing better in identifying patients with active disease (3).

Objectives: To assess in patients with SSc the predictive value of the EUSTAR-AI for disease severity accrual.

Methods: SSc patients from the EUSTAR database with a disease duration from the onset of the first non-Raynaud sign/symptom $\leq 5$ years were first extracted. Patients were considered for the study if they presented the following features: a)availability of items included in the EUSTAR-AI, in the EScSG-AI and in the Medsger severity scale at baseline and yearly for 2 consecutive years; b)availability of vital status at the last observation; c) availability of other disease features known to predict disease progression (male sex, clinical and serological subset).

To capture the disease activity variations over time, we calculated the EUSTAR-AI and EScSG-AI adjusted mean (area under the curve over time divided by time interval). Disease progression was based on the Medsger severity scale and included accrual of a $\Delta \geq 1$ summed severity score and of a $\Delta \geq 1$ severity in each organ systems at the 2 year follow-up visit compared with the initial visit. To explore specific determinants of disease progression, logistic regression analysis was carried out. Results: A total of 549 patients satisfied the entry criteria. At univariate logistic regression analysis (among sex, age, clinical and serological subset, EScSG-AI and EUSTAR-AI adjusted mean and baseline severity score), EScSG-AI adjusted mean (OR 1.41 95\% Cl 1.20-1.67), antiScl70 antibody positivity (OR $1.7295 \% \mathrm{Cl} 1.20-2.47$ ), diffuse subset (OR:1.46 $95 \% \mathrm{Cl} 1.01-2.10$ ) and EUSTAR-Al adjusted mean (OR $1.4195 \% \mathrm{Cl} 1.23-$ 1.61) predicted disease severity accrual. Multivariate analysis revealed that the EUSTAR-Al adjusted mean was the best predictor of disease progression (Table1). Moreover, at multivariate analysis the EUSTAR-Al adjusted mean also predicted severity accrual of lung (OR 1.32), heart (OR 1.40), skin (OR 1.48) and peripheral vascular disease (OR 1.45). Conclusion: The adjusted mean EUSTAR-AI has a distinct predictive value for disease progression and development of severe organ involvement in SSc and works better than EScSG-AI.

\section{REFERENCES}

[1] Valentini G, et al. Ann Rheum Dis 2001;60:592-8.

[2] Nevskaya T, et al. Rheumatology (Oxford). 2017;56:1111-1122.

[3] Valentini G, et al. Ann Rheum Dis. 2017;76:270-276.
Table 1.. Predictive features of severity progression by multivariate regression analysis

\begin{tabular}{lccc}
\hline Predictive factors & OR (IC 95\%) & severity deterioration & p- value \\
\hline Adjusted mean EUSTAR- & $1.41(1.23-$ & $\Delta$ summed severity score $\geq 1$ & $<0,0001$ \\
Al & $1.61)$ & & \\
Adjusted mean EUSTAR- & $1.32(1.14-$ & $\Delta$ lung severity score $\geq 1$ & 0,0002 \\
Al & $1.54)$ & & \\
Adjusted mean EUSTAR - & $1.40(1.15-$ & $\Delta$ heart severity score $\geq 1$ & 0,0005 \\
Al age & $1.70)$ & & 0,0223 \\
& $1.03(1.01-$ & & \\
Adjusted mean EUSTAR-AI & $1.05)$ & $\Delta$ Skin severity score $\geq 1$ & 0,0002 \\
age & $1.48)$ & & 0,0359 \\
& $0.97(0.95-$ & & \\
& $0.99)$ & $\Delta$ Peripheral Vascular severity & $<0,0001$ \\
Adjusted mean EUSTAR-Al & $1.45(1.24-$ & score $\geq 1$ & \\
& $1.70)$ & &
\end{tabular}

Disclosure of Interests: Serena Fasano: None declared, Veronica Giacco: None declared, Antonella Riccardi: None declared, Valentina Messiniti: None declared, ALESSANDRA VACCA: None declared, Oliver Distler Grant/research support from: Prof. Distler received research funding from Actelion, Bayer, Boehringer Ingelheim and Mitsubishi Tanabe to investigate potential treatments of scleroderma and its complications, Consultant for: Prof. Distler has/had consultancy relationship within the last 3 years with Actelion, AnaMar, Bayer, Boehringer Ingelheim, ChemomAb, espeR are foundation, Genentech/Roche, GSK, Inventiva, Italfarmaco, iQvia, Lilly, medac, Medlmmune, Mitsubishi Tanabe Pharma, Pharmacyclics, Novartis, Pfizer, Sanofi, Serodapharm and UCB in the area of potential treatments of scleroderma and its complications. In addition, he had/has consultancy relationship within the last 3 years with $A$. Menarini, Amgen, Abbvie, GSK, Mepha, MSD, Pfizer and UCB in the field of arthritides and related disorders, Otylia Kowalka Bielecka Consultant for: "OK-B received consulting fees or other remuneration from Bayer, Boehringer Ingelheim, Inventiva, Medac, Novartis and Roche", Yannick Allanore Grant/research support from: Inventiva, F Hoffman La-Roche, Sanofi, BMS, Pfizer, Consultant for: Actelion, Bayer, BMS, Boehringer, Roche, Sanofi, Gabriele Valentini Grant/research support from: MSD, Phizer, Consultant for: MSD, Phizer, biogen, Speakers bureau: MSD, amgen, biogen, lilly, sanofi, phizer

DOI: 10.1136/annrheumdis-2019-eular.3485

\section{SAT0274 \\ THE EFFECT OF RITUXIMAB ON LUNG FUNCTION AND SKIN SCORE IN SYSTEMIC SCLEROSIS-ASSOCIATED INTERSTITIAL LUNG DISEASE. LONG-TERM OBSERVATION}

Liudmila Garzanova ${ }^{1}$,Lidia P. Ananyeva ${ }^{1}$, Olga Koneva ${ }^{1}$, Oxana Desinova ${ }^{1}$, Olga Ovsyannikova', Mayya Starovoytova', Alexander Volkov²,

Svetlana Glukhova ${ }^{2} .{ }^{1}$ V.A. Nasonova Research Institute of Rheumatology, Laboratory of microcirculation and inflammation, Moscow, Russian Federation; ${ }^{2} \mathrm{~V}$. A. Nasonova Research Institute of Rheumatology, Diagnostic department, Moscow, Russian Federation

Background: There is a large clinical experience about the efficiency of rituximab (RTX) for the treatment of systemic sclerosis (SSc). There are several studies showing the decrease in skin induration and interstitial fibrosis in the lungs as the effect of therapy. However, there are not many long-term observations.

Objectives: To describe the efficacy of RTX on lung function and skin score in patients with systemic sclerosis-associated interstitial lung dis ease, in long-term follow-up.

Methods: This study included 71 patients (pts) with SSc. Data were collected prospectively. The mean follow-up period was 42 mo (12-72). Mean age was 46 years (17-66), female-59 (83\%), diffuse cutaneous subset of the disease had 42 (59\%), Scl-70 positivity- $73 \%$ of pts. Duration of the disease was $5,6 \pm 4,4$ yrs. All pts received concomitant treatment with low dose prednisolone and $45 \%$ - with immunosupressants. The following indicators were evaluated: forced vital capacity,\% predicted (FVC) diffusing capacity for carbon monoxide,\% predicted (DLCO) and Rodnan skin score (mRss) over a periods of 12-18 months (point 1), 24-30 months (point 2), 36-42 months (point 3), 48-54 months (point 4) and 60-72 months (point 5) after the start of therapy. The results are presented in the form of mean values, delta, median, upper and lower quartile. 
Results: In point $1(\mathrm{n}=71)$ the cumulative mean dose of RTX was 1,43 $\pm 0,6 \mathrm{gr}$. The mRss decreased from $11,3 \pm 9,6$ to $8 \pm 6,6$ ( $p=0,000007$ ). FVC increased from $77,4 \pm 19,9$ to $82,6 \pm 20,7 \% \quad(p=0.0001)$. DLCO remained stable (from $47,0 \pm 18,5$ to $47,23 \pm 16,7 \%$ ). In point $2(n=55)$ the cumulative mean dose of RTX was $2,97 \pm 0,8$ gr. $\Delta$ mRss - 5,4 (median 3; 25th\% 0; 75th\% 10). $\triangle$ FVC - 7,5\% (median 8,2; 25th\% $-1,1 ; 75$ th\% 14,4). $\triangle$ DLCO - 0,21\% (median $-0,2 ; 25$ th\% $-6,2 ; 75$ th $\% 6,6$ ). In point 3 $(n=36)$ the cumulative mean dose of RTX was $3,45 \pm 1,3$ gr. $\Delta$ mRss $-5,1$ (median 3,5; 25th\% 0; 75th\% 9). $\Delta \mathrm{FVC}-9,3 \%$ (median 7,7; 25th\% 1,$45 ; 75$ th $\%$ 15,3). $\Delta$ DLCO - 3,4\% (median 3,6; 25th\% 2,45; 75th\% $7,76), p=0,02$. In point $4(n=24)$ the cumulative mean dose of RTX was $3,96 \pm 1,1$ gr. $\Delta$ mRss - 5,3 (median $3 ; 25$ th $\% \quad 0 ; 75$ th $\% \quad 10$ ). $\Delta$ FVC 12,2\% (median 7,9; 25th\% 1,1; 75th\% 24,2). $\Delta$ DLCO - 3,9\% (median $0,45 ; 25$ th $\%-0,95 ; 75$ th $\% 6,8)$. In point $5(n=17)$ the cumulative mean dose of RTX was $5,15 \pm 1,7$ gr. It should be noted that this group included patients with initially the lowest DLCO (below 40\%). $\Delta$ mRss 7,3 (median 5; 25th\% 1; 75th\% 14). $\triangle$ FVC - 13,2\% (median 11; 25th\% 8,$7 ; 75$ th\% 23,4). $\Delta$ DLCO - 5,9\% (median 1,6; 25th\% $-4,8 ; 75$ th\% 13,8). Conclusion: The results of this study confirm the data on the positive effect of RTX in patients with SSc (decrease of skin induration, increase of FVC, stabilization of DLCO). The decrease of skin score is accompanied by the improvement of lung function indicators. In our study, there was a significant increase of DLCO associated with long-term treatment (over $36 \mathrm{mo}$ ) and a cumulative dose of RTX over $3,45 \pm 1,3 \mathrm{gr}$. Patients with initially lower DLCO can achieve a significant improvement by the 60th month of RTX therapy. Our work shows that patients with SScassociated interstitial lung disease are required long-term treatment with RTX (at least 3-5 years) to achieve an obvious improvement of the lung function.

\section{REFERENCE}

[1] Jordan S, Distler JH, Maurer B, Huscher D, van Laar JM, Allanore Y. et al; EUSTAR Rituximab study group. Effects and safety of rituximab in systemic sclerosis: an analysis from the European Scleroderma Trial and Research (EUSTAR) group. Ann Rheum Dis 2015;74(6):1188-94.

Disclosure of Interests: None declared DOI: 10.1136/annrheumdis-2019-eular.5565

\section{SAT0275 PERFORMANCE OF THE ANTISYNTHETASE ANTIBODIES AND THEIR INDIRECT IMMUNOFLUORESCENCE PATTERNS IN THE ANTISYNTHETASE SYNDROME DIAGNOSIS}

Martín Greco ${ }^{1}$, María Jesús García de Yébenes ${ }^{2}$,Inmaculada Alarcón ${ }^{1}$, ${ }^{3,4}$ Anahy Brandy-Garcia ${ }^{4}$, Iñigo Rua-Figueroa ${ }^{1}$, Estíbaliz Loza ${ }^{2}$, Teresa Oton ${ }^{2}$, Francisco Rubiño ${ }^{1}$, Juan Manuel Díaz ${ }^{1}$, Félix Francisco ${ }^{1}$, Soledad Ojeda ${ }^{1}$, Loreto Carmona ${ }^{2} .{ }^{1}$ Hospital Universitario de Gran Canaria Dr. Negrín., Las Palmas, Spain; ${ }^{2}$ Instituto de Salud Musculoesquelética Inmusc, Madrid, Spain; ${ }^{3}$ Hospital Universitari Germans Trias i Pujol, Barcelona, Spain $;{ }^{4}$ Hospital Universitario Central de Asturias, Oviedo, Spain

Background: The antisynthetase syndromes (ASSD) are characterized by the presence of anti-aminoacyl transfer RNA synthetase (ARS) autoantibodies; which difficult the binding of amino acids to the transfer RNA during the protein synthesis. ARS can be detected by indirect immunofluorescence (IIF), and can be identified by immunoblot assay and ELISA (Enzyme-Linked ImmunoSorbent Assay) and immunoblotting. The main clinical features of the ASSD are myositis, arthritis, interstitial lung disease, Raynaud's phenomenon, mechanic hands, and fever. Two ASSD diagnosis criteria have been developed; those proposed by Connors, and the stricter criteria proposed by Solomon $(1,2)$.

Objectives: To evaluate the performance of the ARS and their IIF patterns in the ASSD diagnosis.

Methods: We performed an observational retrospective study in one center during the period 06/2008-06/2018. We searched all the myositis immunoblots (Euroimmun assay) requested by the Rheumatologists under suspicion of ASSD or myositis. We assessed: 1) the rate of cases with positive ARS; 2) the rate of cases with Connor's or Solomon's diagnosis criteria fulfillment; and 3 ) their relation with the IIF patterns (Hep-2 cells; $\geq 1 / 80$ ) evaluated by an expert in autoimmune tests.

Results: A total of 140 myositis immunoblots were searched. Twentyseven cases (19.3\%) presented positive ARS: anti-Jo1 ( $n=13)$, anti-PL-12 $(n=7)$, anti-PL-7 $(n=1)$, anti-EJ $(n=2)$, and anti-OJ $(n=4)$. Twenty-five of these $(17.9 \%)$ fulfilled Connors' criteria, and $15(10.7 \%)$ additionally met Solomon's criteria. Thus, the fulfillment of Connor's and Solomon's criteria in patients with a positive ARS was of $92.6 \%$ and $55.5 \%$, respectively.

All cases (100\%) with positive ARS presented positive immunofluorescence: $19(70.4 \%)$ showed a cytoplasmic pattern (10 of them with an associated nuclear pattern) and 8 cases $(29.6 \%)$ presented only a nuclear pattern. On the other hand, 99 of the 113 cases $(87.6 \%)$ with negative ARS presented positive IIF: 29 (25.7\%) showed a cytoplasmic pattern (21 of them with an associated nuclear pattern) and 42 cases $(37.2 \%)$ presented only a nuclear pattern.

Correlating the ARS positivity, IIF pattern and the diagnosis criteria fulfillment:

- 13 of 15 cases (86.6\%) with positive ARS and Solomon's criteria fulfillment presented a cytoplasmic pattern; and 2 of 15 cases (13.3\%) presented only a nuclear pattern.

- 13 of 19 cases (68.4\%) with positive ARS and cytoplasmic pattern fulfilled Solomon's criteria; and 6 only fulfilled those from Connors'.

Conclusion: One-fifth of the immunoblots requested by Rheumatologists presented positive ARS; almost all these cases fulfilled Connor's criteria, and more than a half fulfilled the stricter Solomon's criteria. All patients with positive ARS, and a high rate of those without ARS, presented positive IIF. The presence of a cytoplasmic pattern was considerably higher in patients with ARS positivity and in those that met Solomon's criteria. Thus, our results suggests that in patients evaluated by a Rheumatologist, with clinical suspicion of ASSD or myositis and with ARS positivity, the probability of fulfilling Solomon's criteria is higher when the IIF presents a cytoplasmic pattern than when only a nuclear pattern is observed. Nevertheless, presenting only a nuclear pattern does not exclude the detection of ARS in the myositis immunoblot and the fulfillment of Solomon's criteria.

\section{REFERENCES}

[1] Solomon J, et al. Jornal brasileiro de pneumologia. 2011;37(1):100-9.

[2] Connors GR, et al. Chest. 2010;138(6):1464-74.

Disclosure of Interests: Martín Greco: None declared, María Jesús García de Yébenes: None declared, Inmaculada Alarcón: None declared, Anahy Brandy-Garcia: None declared, Iñigo Rua-Figueroa: None declared, Estíbaliz Loza Grant/research support from: Roche, MSD, Pfizer, Abbvie, BMS, UCB, Actelion, Celgene, Grunenthal and Sanofi, Teresa Oton: None declared, Francisco Rubiño: None declared, Juan Manuel Díaz: None declared, Félix Francisco: None declared, Soledad Ojeda: None declared, Loreto Carmona Grant/research support from: Abbvie, Actelion, Astellas, BMS, Eisay, Gebro Pharma, Grünenthal, Leo Pharma, Lilly, MSD, Novartis, Pfizer, Roche, Sanofi-Aventis and UCB Pharma, Paid instructor for: Novartis

DOI: 10.1136/annrheumdis-2019-eular.7182

\section{SAT0276 STUDY OF THE EPIDEMIOLOGICAL, CLINICAL AND ANALYTICAL CHARACTERISTICS IN PATIENTS WITH SYSTEMIC SCLEROSIS AND CANCER IN VALL D'HEBRON HOSPITAL}

Maria Roca Herrera ${ }^{1}$, Alfredo Guillén del Castillo ${ }^{1}$, Eduardo Callejas Moraga ${ }^{2}$, David Bernal Bello ${ }^{3}$, Jorge Hernando Cubero ${ }^{4}$, Natalia Iriarte Gay de Montella ${ }^{1}$ Vicent Fonollosa Pla', Carmen Pilar Simeón-Aznar ${ }^{1}$. ${ }^{1}$ Vall d'Hebron Hospital, INTERNAL MEDICINE, Barcelona, Spain; ${ }^{2}$ Parc Taulí Hospital, INTERNAL MEDICINE, Sabadell, Spain; ${ }^{3}$ Fuenlabrada Hospital, INTERNAL MEDICINE Fuenlabrada, Spain; ${ }^{4}$ Vall d'Hebron Hospital, ONCOLOGY, Barcelona, Spain

Background: Scleroderma or systemic sclerosis (SSc) is a systemic, chronic autoimmune disease characterized by great clinical heterogeneity. In recent years, studies have proven that there is a relationship between SSc and neoplasia.

SSc is associated with an increased risk of certain types of cancer, particularly lung, liver, hematological, non-melanoma skin and urothelial cancer. Despite this increasement, the relative risk of developing cancer is still low in these patients. In the literature, neoplasms have been described in $3-11 \%$ of patients with SSc.

Objectives: Our objective is to analyze the epidemiological, clinical and analytical characteristics previously described as possibly linked to the development of a cancer in patients with systemic sclerosis (SSc) in the Vall d'Hebron Hospital cohort.

Methods: We analyzed 583 patients in the Vall d'Hebron Hospital cohort of SSc. The inclusion criteria were age $>18$ years and the diagnosis of SSc limited, diffuse and SSc sine scleroderma. The different variables were analyzed by univariate statistical analysis with SPSS v21. 